\title{
Somatostatin Signaling in Neuronal Cilia Is Critical for Object Recognition Memory
}

\author{
Emily B. Einstein, ${ }^{1 \star}$ Carlyn A. Patterson, ${ }^{1 \star}$ Beverly J. Hon, ${ }^{1}$ Kathleen A. Regan, ${ }^{1}$ Jyoti Reddi, ${ }^{1}$ David E. Melnikoff, ${ }^{1}$ \\ Marcus J. Mateer, ${ }^{1}$ Stefan Schulz, ${ }^{2}$ Brian N. Johnson, ${ }^{1}$ and Melanie K. Tallent ${ }^{1}$ \\ ${ }^{1}$ Department of Pharmacology and Physiology, Drexel University College of Medicine, Philadelphia, Pennsylvania 19102, and ${ }^{2}$ Department of Pharmacology \\ and Toxicology, Friedrich-Schiller-University, D-07747 Jena, Germany
}

\begin{abstract}
Most neurons possess a single, nonmotile cilium that projects out from the cell surface. These microtubule-based organelles are important in brain development and neurogenesis; however, their function in mature neurons is unknown. Cilia express a complement of proteins distinct from other neuronal compartments, one of which is the somatostatin receptor subtype $\mathrm{SST}_{3}$. We show here that $\mathrm{SST}_{3}$ is critical for object recognition memory in mice. sst 3 knock-out mice are severely impaired in discriminating novel objects, whereas they retain normal memory for object location. Further, systemic injection of an $\mathrm{SST}_{3}$ antagonist (ACQ090) disrupts recall of familiar objects in wild-type mice. To examine mechanisms of $\mathrm{SST}_{3}$, we tested synaptic plasticity in CA1 hippocampus. Electrically evoked long-term potentiation (LTP) was normal in sst 3 knock-out mice, while adenylyl cyclase/cAMP-mediated LTP was impaired. The SST ${ }_{3}$ antagonist also disrupted cAMP-mediated LTP. Basal cAMP levels in hippocampal lysate were reduced in sst3 knock-out mice compared with wild-type mice, while the forskolin-induced increase in cAMP levels was normal. The $\mathrm{SST}_{3}$ antagonist inhibited forskolin-stimulated cAMP increases, whereas the $\mathrm{SST}_{3}$ agonist L-796,778 increased basal cAMP levels in hippocampal slices but not hippocampal lysate. Our results show that somatostatin signaling in neuronal cilia is critical for recognition memory and suggest that the cAMP pathway is a conserved signaling motif in cilia. Neuronal cilia therefore represent a novel nonsynaptic compartment crucial for signaling involved in a specific form of synaptic plasticity and in novelty detection.
\end{abstract}

\section{Introduction}

Many cells, including neurons, possess a single primary cilium that acts as a compartmentalized signaling structure. Signal transduction in many types of primary (i.e., nonmotile) cilia involves coupling of G-protein-coupled receptors to adenylyl cyclase (AC) (Banizs et al., 2005; Masyuk et al., 2006; Schmid et al., 2007; Takeuchi and Kurahashi, 2008). Mutations in ciliary genes lead to polycystic kidney disease, the most prevalent human genetic disease (Smith et al., 2006). Several such "ciliopathies" present diverse clinical phenotypes that include cognitive defects, such as Bardet-Biedl syndrome (BBS), Joubert syndrome, Meckel-Gruber syndrome (Adams et al., 2007), and hydrocephalus (Ibañez-Tallon et al., 2004; Town et al., 2008). Two different BBS-related proteins have been shown to be critical

Received 0ct. 26, 2009; revised Jan. 18, 2010; accepted Feb. 14, 2010.

This work was supported by National Institutes of Health Grants NS38633 and NS048241, a Drexelmed Translational Tobacco Funds Grant (Pennsylvania Department of Health) to M.K.T., Drexel University College of Medicine Summer Undergraduate Research Fellowship Program (B.H., C.A.P., and K.A.R.), and Drexel University College of Medicine start-up funds. We thank Dr. Daniel Hoyer and Dr. Herbert Schmid (Novartis) for providing ACQ090, Dr. Ute Hochgeshwender (Duke University School of Medicine) for the sst3 and sst4 knock-out mice, Dr. James Schaeffer (Merck) for the sst2 knock-out mice, and Dr. Luis de Lecea (Stanford University School of Medicine) for the sst2/ sst4double knock-outs. We thank Ms. Jennifer Otway and Mr. Christopher Watson for assisting with the LTP experiments, and Ms. Rebecca Jay for her contribution to the behavioral studies. We would also like to thank Dr. James E. Barrett for helpful comments on this manuscript.

*E.B.B. and C.A.P. contributed equally to this work.

Correspondence should be addressed to Melanie K. Tallent, Department of Pharmacology and Physiology, Drexel University College of Medicine, 245 North 15th Street, Philadelphia, PA 19102. E-mail: mtallent@drexelmed.edu. D01:10.1523/JNEUROSC1.5295-09.2010

Copyright $\odot 2010$ the authors $\quad 0270-6474 / 10 / 304306-09 \$ 15.00 / 0$ to localization of G-protein-coupled receptors, including somatostatin (SST) receptor subtype 3 ( $\mathrm{SST}_{3}$ ), to neuronal cilia (Berbari et al., 2008a).

Although critical in brain development and neurogenesis (Breunig et al., 2008; Han et al., 2008; Spassky et al., 2008), the function of cilia on mature neurons is unknown. Neuronal cilia possess a complement of cilia-specific proteins, such as $\mathrm{SST}_{3}$. The cilia-specific expression of this G-protein-coupled receptor was first shown by immunohistochemistry (Händel et al., 1999) and more recently confirmed with a fluorescently tagged receptor (Berbari et al., 2008a). A consensus sequence that targets $\mathrm{SST}_{3}$ to cilia has recently been identified and is located in the third intracellular loop (Berbari et al., 2008b).

SST-containing interneurons are abundant in cortex and hippocampus, brain regions important in cognitive processing. SST expression in cortex and hippocampus is significantly reduced in Alzheimer's disease, and this reduction is correlated with cognitive decline, suggesting this peptide may be critical in cognitive processing (Burgos-Ramos et al., 2008). Previous studies examining the role of SST in learning and memory have produced conflicting results, suggesting both facilitating and inhibitory actions on learning and memory (Baraban and Tallent, 2004). These inconsistencies could be caused by nonspecificity in the available pharmacological tools or the mixture of SST receptor subtypes expressed in hippocampus and cortex.

To examine cilia function and signaling in mature central neurons, we took advantage of the exclusive localization of $\mathrm{SST}_{3}$ to neuronal cilia, and examined the function of this receptor 
using a knock-out mouse and a selective antagonist. Our results show that $\mathrm{SST}_{3}$ receptors are required for object recognition but not spatial memory. In sst 3 knock-out mice, novelty detection is impaired at a $1 \mathrm{~h}$ but not a $5 \mathrm{~min}$ retention interval. These results are supported by the finding that a systemically active $\mathrm{SST}_{3}$ antagonist, ACQ090, impaired object recognition in wild-type mice. Additionally, long-term potentiation (LTP) in CA1 hippocampus evoked by direct activation of AC with forskolin is reduced in sst3 knock-outs, whereas electrically evoked LTP is normal. The $\mathrm{SST}_{3}$ antagonist also impairs AC-mediated LTP. Our data indicate that $\mathrm{SST}_{3}$ is critical for recall of object information and synaptic plasticity induced by direct activation of AC. Thus, an important function of neuronal cilia is detection of SST, leading to extrasynaptic signaling events via $\mathrm{SST}_{3}$ that are critical to object memory.

\section{Materials and Methods}

Mice. We used 10- to 20-week-old male and female sst2, sst3, and sst4 knock-out mice generated as previously described (Zheng et al., 1997; Qiu et al., 2008). No gender differences were observed in the tested paradigms; therefore, we pooled data from each gender. The knock-out strains were backcrossed at least 10 generations to C57BL/6J. Wild-type mice were the progeny of either sst $3^{+/-}$or C57BL/6J mice (Jackson Laboratories). Mice were housed with their siblings by gender and received water and food ad libitum. The animal room was kept at $70^{\circ} \mathrm{F}$ and a $71 \%$ humidity level in a $12 \mathrm{~h}$ light/dark cycle. All experiments were performed during the light phase of the cycle. All animal studies were approved by Drexel College of Medicine Institutional Animal Care and Use Committee and in accordance with the guidelines of the National Institutes of Health and the Society for Neuroscience.

Novel object recognition. At least four groups of mice were tested at different times for each strain. Age-matched wild-type mice were included in each test group. Mice were habituated the day before testing for $10 \mathrm{~min}$ in an empty box $\left(48 \times 43 \times 38 \mathrm{~cm}^{3}\right)$ that was evenly illuminated. The box was cleaned after each trial with $50 \%$ ethanol to eliminate any odors and any debris was removed. The following day, mice were placed back in the box with two objects placed $13 \mathrm{~cm}$ from either end of the long axis. The objects consisted of two similar wood blocks, $\sim 5 \times 5 \times 5 \mathrm{~cm}^{3}$. During a $5 \mathrm{~min}$ interval, the number of times the mouse approached, oriented toward, and sniffed each object was recorded. After a delay (5 min or $1 \mathrm{~h}$ ), the mouse was again placed in the maze with one of the same objects and a novel wooden block that differed in both shape and color. The replacement of objects was random. The mice were given 5 min to approach the objects. Mice who failed to approach a cumulative of six times, showed any signs of unusual behavior or distress, spent $>60 \%$ of the time on one side of the box, or showed a distinct preference $(\geq 60 \%)$ for either object during the original presentation phase $(<5 \%$ of the mice) were excluded from the experiment. For three-trial learning, mice were given three presentation trials lasting $5 \mathrm{~min}$ with a $10 \mathrm{~min}$ intertrial interval and tested for object recognition $1 \mathrm{~h}$ after the end of the last trial. Preference index was defined as the number of approaches to each object (novel or familiar) divided by the total number of approaches to both objects. Intraperitoneal injections were given $30 \mathrm{~min}$ before the sample or test phase. ACQ090 was dissolved in DMSO and diluted in sterile saline. The final concentration of DMSO was kept at $0.1 \%$ (vehicle).

Object displacement test. We tested spatial memory using a similar paradigm as described for testing object recognition. This allows a more direct comparison of different types of memory, since the environment, stress levels, and sensory and motor demands are the same (Dere et al., 2007). Pilot studies showed a two-trial training strategy was needed to establish consistent preference for the displaced object in wild-type mice. Therefore, the sample phase consisted of two $5 \mathrm{~min}$ trials with a $10 \mathrm{~min}$ intertrial interval. Otherwise, habituation and training were the same as described for the object recognition memory (ORM) task. For the test phase, after a 1 or $2 \mathrm{~h}$ retention interval, one of the objects was displaced from its position during the sample phase. The stationary object was always located in the center of the box, and the displaced object was always moved to the opposite corner, although the starting corner placement was randomized. Using this strategy, the angles of the displaced object to the long axis of the boxes and to the stationary object remained constant, so that distal cues were necessary for navigation. Equal preference for the corner object and the central object was noted in the training phase of the test (see Fig. 7). The number of approaches to each object was recorded and preference index was calculated as in ORM testing.

Extracellular recording. Hippocampal slices were prepared as previously described (Baratta et al., 2002; Qiu et al., 2008). Briefly, male or female mice (6-14 weeks) were anesthetized with isoflurane (4\%) and decapitated, and the brains were removed rapidly and placed in ice-cold artificial CSF (ACSF), gassed with $95 \% \mathrm{O}_{2} / 5 \% \mathrm{CO}_{2}$ (carbogen) of the following composition (in $\mathrm{mM}$ ): $130 \mathrm{NaCl}, 3.5 \mathrm{KCl}, 1.25 \mathrm{NaH}_{2} \mathrm{PO}_{4}, 1.5$ $\mathrm{MgSO}_{4} \cdot 7 \mathrm{H}_{2} \mathrm{O}, 2 \mathrm{CaCl}_{2} \cdot 2 \mathrm{H}_{2} \mathrm{O}, 24 \mathrm{NaHCO}_{3}, 10$ glucose. Four-hundredmicrometer-thick hippocampal slices were cut on a tissue chopper. Slices were placed in a water bath at $33^{\circ} \mathrm{C}$ for $40 \mathrm{~min}$, after which they were kept at room temperature until being placed in the recording chamber. Slices were completely submerged and continuously superfused with gassed $\operatorname{ACSF}\left(31^{\circ} \mathrm{C}\right)$ at a constant rate $(2.5-3 \mathrm{ml} / \mathrm{min})$ for the remainder of the experiment. Drugs and peptides were added to the bath from stock solutions at known concentrations.

We acquired data with an Axoclamp 2B amplifier (Molecular Devices) by D/A sampling using pCLAMP acquisition software (Molecular Devices). Extracellular field EPSPs (fEPSPs) were recorded in the CA1 pyramidal cell layer using a glass micropipette filled with $3 \mathrm{M} \mathrm{NaCl}$. We evoked Schaffer collateral synaptic responses at $0.033 \mathrm{~Hz}$ with a bipolar, tungsten stimulating electrode placed near to the stratum radiatum. Stable baseline fEPSPs were confirmed by stimulating at $40-50 \%$ of the maximal field amplitude for 20-30 min before beginning experiments.

We generated LTP with two high-frequency trains (HFTs) of $1 \mathrm{~s}$ each at $100 \mathrm{~Hz}, 20 \mathrm{~s}$ apart, using the test stimulus intensity. Alternatively, we evoked LTP using $50 \mu \mathrm{M}$ forskolin (in 0.1\% DMSO), $30 \mu \mathrm{M}$ isobutylmethylxanthine (IBMX; in 0.1\% DMSO), and $5 \mu \mathrm{M}$ bicuculline methochloride (a submaximal concentration; dissolved in water) for $15 \mathrm{~min}$, after which drugs were washed out. Responses at $40-50 \%$ of maximal baseline amplitudes were evoked and recorded every $30 \mathrm{~s}$ throughout the experiment. The mean initial slopes (between the 0 and 50\% points on the rising phase) of two averaged fEPSPs were compared between the slice groups. Recordings where a population spike contaminated the rising phase of the fEPSP were excluded from analysis.

Immunohistochemistry. $\mathrm{SST}_{3}$ immunostaining was performed as previously described (Händel et al., 1999). Mice were perfused with $4 \%$ paraformaldehyde and $0.2 \%$ picric acid; brains were removed and postfixed for $2 \mathrm{~h}$ in the same fixative. We performed immunohistochemistry on free-floating sections using polyclonal rabbit anti-SST ${ }_{3}$ antibody (7986) at a dilution of 1:20,000. Staining of primary antibody was detected using the biotin amplification procedure as described previously (Händel et al., 1999). Briefly, tissue sections were transferred to biotinylated goat anti-rabbit IgG and then incubated with avidin-biotinylated peroxidase complex. Bound peroxidase was reacted with biotinylated tyramine, which was then visualized with streptavidin-Cy3 for single immunofluorescence.

For immunohistochemical analysis of type III adenylyl cyclase, mice were perfused with $4 \%$ paraformaldehyde, and brains were removed and placed in paraformaldehyde for overnight postfixation. The brains were then moved to $30 \%$ sucrose until sinking. Forty-micrometer sections were made on a Leica cryostat. We incubated free-floating sections with $0.2 \%$ Triton X-100 for 30 min then and $0.2 \%$ Triton X-100/5\% normal goat serum for $1 \mathrm{~h}$. Sections were then incubated with 1:500 ACIII antibody (Santa Cruz Biotechnology; catalog \#sc-588) overnight at $4^{\circ} \mathrm{C}$, rinsed $3 \times 10 \mathrm{~min}$ in $\mathrm{PBS}$, and then incubated in secondary antibody (Alexafluor 488-conjugated goat anti-rabbit IgG, Invitrogen) for $1 \mathrm{~h}$ at room temperature. After three $10 \mathrm{~min}$ rinses with $\mathrm{PBS}$, sections were mounted on slides using Vectashield containing DAPI to stain for nuclei (blue) and imaged using a Zeiss confocal microscope (Axioimager Z1m with LSM5 exciter laser module and software). ACIII-stained cilia in CA1 of wild-type mice $(n=3)$ and sst 3 knock-out mice $(n=3)$ were counted using ImageJ analysis software (http://rsb.info.nih.gov/ij). Cilia were detected using two criteria: signal intensity in the red channel (threshold $>$ 
50) and size (area $>1.3 \mu \mathrm{m})$. Cilia detection was confirmed with visual inspection. Length and width of ACIII-stained cilia were measured manually using the LSM image browser (Zeiss) to make a three-dimensional projection of $0.2 \mu \mathrm{M}$ confocal stacks. Since the highest resolution occurs within the $x y$ plane, we selected cilia with this approximate orientation for measurement. We measured 20 cilia per image in three different wild-type and sst3 knock-out mice.

Meaurement of cAMP levels. We used an enzyme immunoassay kit (Cayman Scientific) to measure cAMP levels from wild-type and sst3 knock-out mice. Hippocampi were dissected from brain as described for electrophysiological studies. One hippocampus was frozen in liquid nitrogen and put in lysis buffer ( $50 \mathrm{~mm}$ Tris $\mathrm{HCl}, 1 \mathrm{~mm} \mathrm{EGTA,} 5 \mathrm{~mm} \mathrm{MgCl}_{2}$, $100 \mathrm{~mm} \mathrm{NaCl}, 30 \mu \mathrm{M}$ IBMX, and 0.5\% Sigma protease inhibitor cocktail). The other hippocampus was bisected, frozen in liquid nitrogen, and weighed; one-half was put in 5\% trichloroacetic acid (TCA) for extraction of cAMP, and the other half was placed into buffer for protein measurement (Coomassie Protein Assay Reagent, Pierce). To prepare hippocampal lysates, tissue was homogenized and centrifuged at $1000 \times$ $g$, and the supernatant was removed. For measurement of forskolinstimulated cAMP in lysate, we added 100-200 $\mu \mathrm{g}$ of tissue to incubation buffer containing $50 \mathrm{~mm}$ ATP, $30 \mu \mathrm{M} \mathrm{IBMX}$, and $5 \mathrm{~mm}$ creatine phosphate with and without forskolin $(50 \mu \mathrm{M})$. We incubated the mixture for $10 \mathrm{~min}$ at $37 \%$ in a water bath and stopped the reaction by adding $5 \%$ TCA, which was subsequently extracted with water-saturated ether, with residual ether removed by pipetting and boiling; the assay was performed according to manufacturer directions. For measuring cAMP levels in hippocampal slices, we incubated two to three dorsal hippocampal slices from 10- to 12-week-old wild-type mice for each condition in 12-well plates on nylon mesh nets in carbogen-gassed ACSF for 40 min before addition of drugs. Drugs and/or DMSO was added to each well so that DMSO concentrations were the same for each condition (0.3\%). After 10 min, slices were rapidly moved to $4 \%$ TCA to stop the reaction. Slices were sonicated in TCA, and the suspension was centrifuged at $1000 \times g$. The supernatant was extracted with water-saturated ether and measured for cAMP levels as described above for the lysate preparation. The pellet containing precipitated proteins was solubilized in $1 \mathrm{~N} \mathrm{NaOH}$ and measured for protein concentration using a Lowry Assay (Bio-Rad).

Statistical methods. In behavioral tests, we used unpaired $t$ test (twotailed) to evaluate differences from wild-type mice and knock-out strains, and one-sample $t$ test (two-tailed) to determine a significant preference for the novel object versus random preference $(0.5$; statistiXL, statistiXL.com); we considered $p<0.05$ as statistically significant. For electrophysiology experiments, we used ANOVA to determine significance between strains and drug effects (statistiXL), and considered $p<$ 0.05 as significant. For cilia quantification, we used ANOVA to examine strain differences. All data are reported as mean \pm SEM.

Drugs. Forskolin and bicuculline were purchased from Ascent Pharmaceuticals, ACQ090 was a gift from Novartis, L-796,778 was a gift from Merck, and all other drugs were purchased from Sigma-Aldrich.

\section{Results}

Validation of cilia-specific localization of $\mathrm{SST}_{3}$

Although several independent groups using distinct antibodies have reported cilia-specific localization of $\mathrm{SST}_{3}$ (Händel et al., 1999; Berbari et al., 2008a; Stanić et al., 2009), noncilia staining has also been reported (Hervieu and Emson, 1998; Ramírez et al., 2002). To our knowledge, none of the $\mathrm{SST}_{3}$ antibodies published to date have had their specificity validated in an sst3 knock-out mouse. We therefore performed immunolabeling of $\mathrm{SST}_{3}$ in brains of wild-type and sst 3 knock-out mice using the $\mathrm{SST}_{3}$ antibody (7896) originally describing cilia-specific localization (Händel et al., 1999). In hippocampus of wild-type mice, distinct labeling of cilia can be detected in CA1 (Fig. $1 A, E$ ) and dentate gyrus (Fig. $1 B$ ). However, in hippocampus of sst3 knock-out mice, no such staining is observed (Fig. $1 B, D, F$ ). As reported (Händel et al., 1999), cilia-specific localization of $\mathrm{SST}_{3}$ was found in other brain regions as well, including cortex and hypothalamus
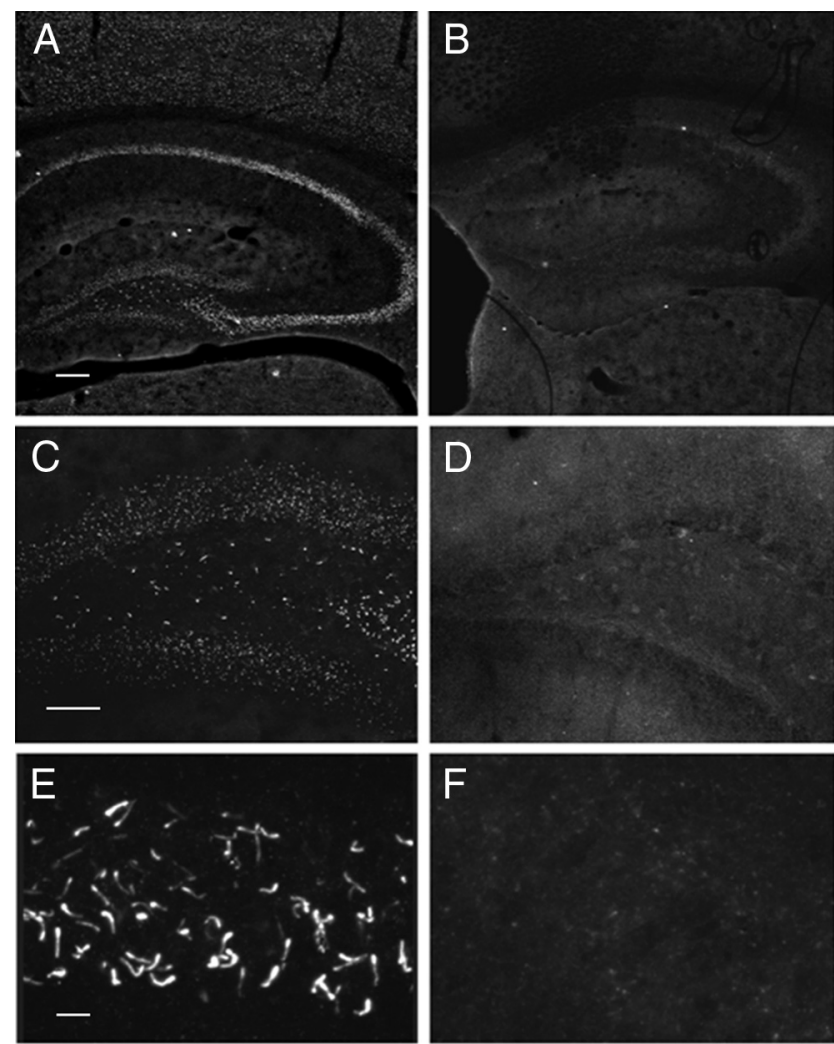

Figure 1. Validation of $\mathrm{SST}_{3}$-specific antibody confirms cilia localization of the receptor. $\boldsymbol{A}-\boldsymbol{F}$, Immunostaining in hippocampus of wild-type mice $(\boldsymbol{A}, \boldsymbol{C}, \boldsymbol{E})$ and sst 3 knock-out mice $(\boldsymbol{B}, \boldsymbol{D}$, $\boldsymbol{F}$ ). $\boldsymbol{A}, \boldsymbol{B}$, Hippocampus; $\boldsymbol{C}, \boldsymbol{D}$, dentate gyrus; $\boldsymbol{E}, \boldsymbol{F}, \mathbf{C A 1}$. Scale bars: $\boldsymbol{A}$ (for $\boldsymbol{A}, \boldsymbol{B}), 200 \mu \mathrm{m}$; $\boldsymbol{C}$ (for $\boldsymbol{C}$, D), $100 \mu \mathrm{m} ; \boldsymbol{E}$ (for $\boldsymbol{E}, \boldsymbol{F}$ ), $10 \mu \mathrm{m}$.
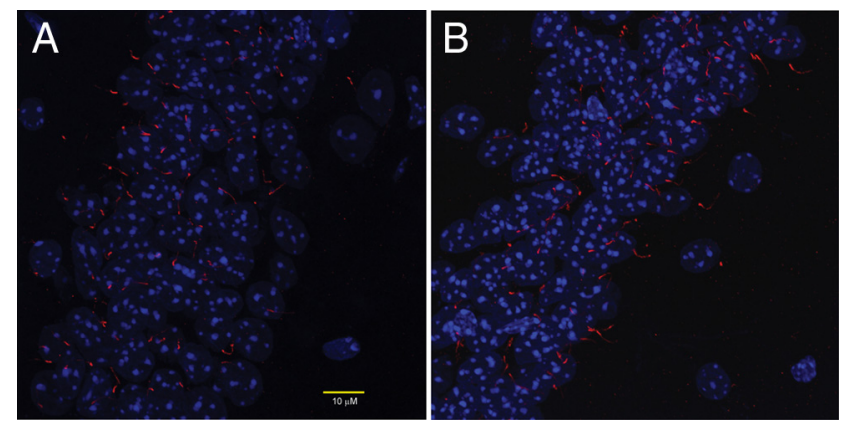

Figure 2. Normal appearance of cilia in CA1 of sst3 knock-out mice. Immunostaining with anti-ACIII (red) antibody reveals no gross disruption of cilia structure or number in sst3 knockout $(\boldsymbol{B})$ versus wild-type $(\boldsymbol{A})$ mice. DAPI (nuclear) staining is in blue.

(data not shown). Thus, we have confirmed the unique localization of $\mathrm{SST}_{3}$ to cilia in mouse brain.

\section{Assessment of cilia structure}

Since knock-out of some cilia-localized proteins can lead to gross disruptions of neuronal cilia structure (Davenport et al., 2007), we performed immunostaining of ACIII (Bishop et al., 2007) to assess the structure and number of cilia in CA1 of wild-type mice $(n=3)$ and sst 3 knock-out mice $(n=3)$. No gross abnormalities of cilia structure were apparent (Fig. 2). We observed no difference in the number of cilia per $102 \times 102 \mu \mathrm{m}$ section between wild-type mice $(35.3 \pm 3.7)$ and sst 3 knock-out mice (33.3 \pm 5.0$)$. Measurements of cilia length (wild-type, $7.5 \pm 0.2 \mu \mathrm{m}$; sst3 knock-outs, $7.4 \pm 0.2 \mu \mathrm{m}$ ), width at tip (wild-type, $0.5 \pm 0.02$ 

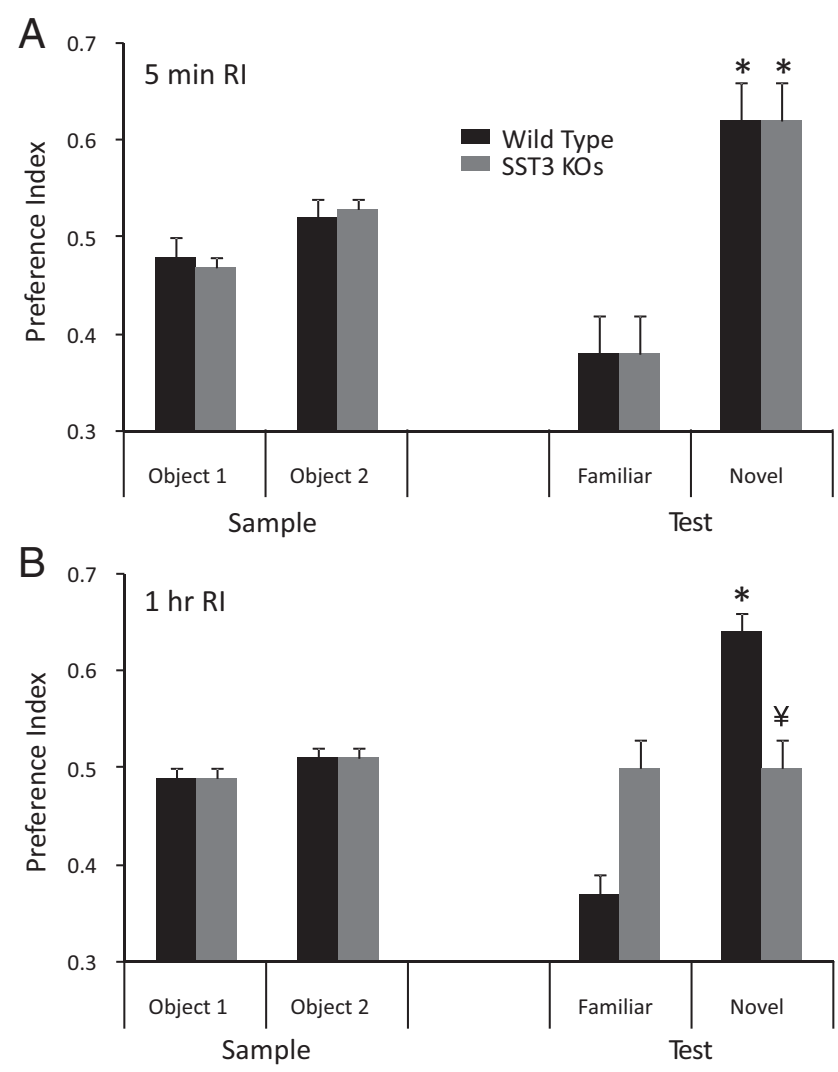

Figure 3. Impairment of ORM in sst3 knock-out mice. $\boldsymbol{A}$, sst3 knock-out mice show no impairment of ORM with a 5 min retention interval between the sample phase and the test phase. Dashed lines in this and subsequent figures indicate equal exploration of both objects. $\boldsymbol{B}$, With a $1 \mathrm{~h}$ delay between the sample phase and the test phase, sst3 knock-out mice, in contrast to wild-type mice, do not show a preference for the novel object. *Significant preference (one-sample $t$ test); ${ }^{*}$ significant difference from wild type (unpaired $t$ test).

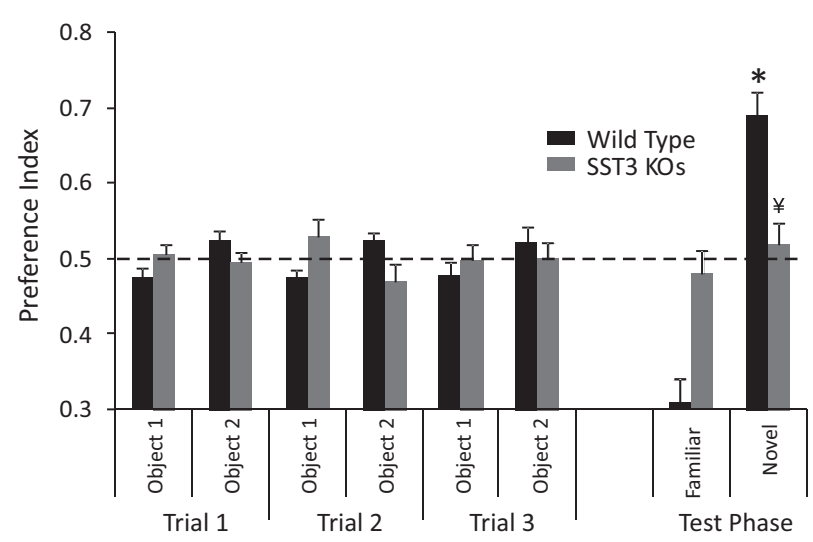

Figure 4. Overtraining does not restore deficit in ORM in sst 3 knock-out mice. The training protocol consisted of three 5 min trials with a 10 min intertrial interval. After a $1 \mathrm{~h}$ delay, mice were tested for their preference for a novel object. *Significant preference (one-sample $t$ test); ${ }^{*}$ significant difference from wild type (unpaired $t$ test).

$\mu \mathrm{m}$; sst3 knock-outs, $0.5 \pm 0.02 \mu \mathrm{m}$ ), and width at base (wildtype, $0.8 \pm 0.03 \mu \mathrm{m}$; sst3 knock-outs, $0.9 \pm 0.03 \mu \mathrm{m}$ ) were not different between wild-type and sst 3 knock-out mice $(322 \times$ $322 \times 30 \mu \mathrm{m}$ sections; $n=3$ mice each). These findings suggest that cilia function in $s s t 3$ knock-outs may be normal apart from a lack of sst3 signaling.
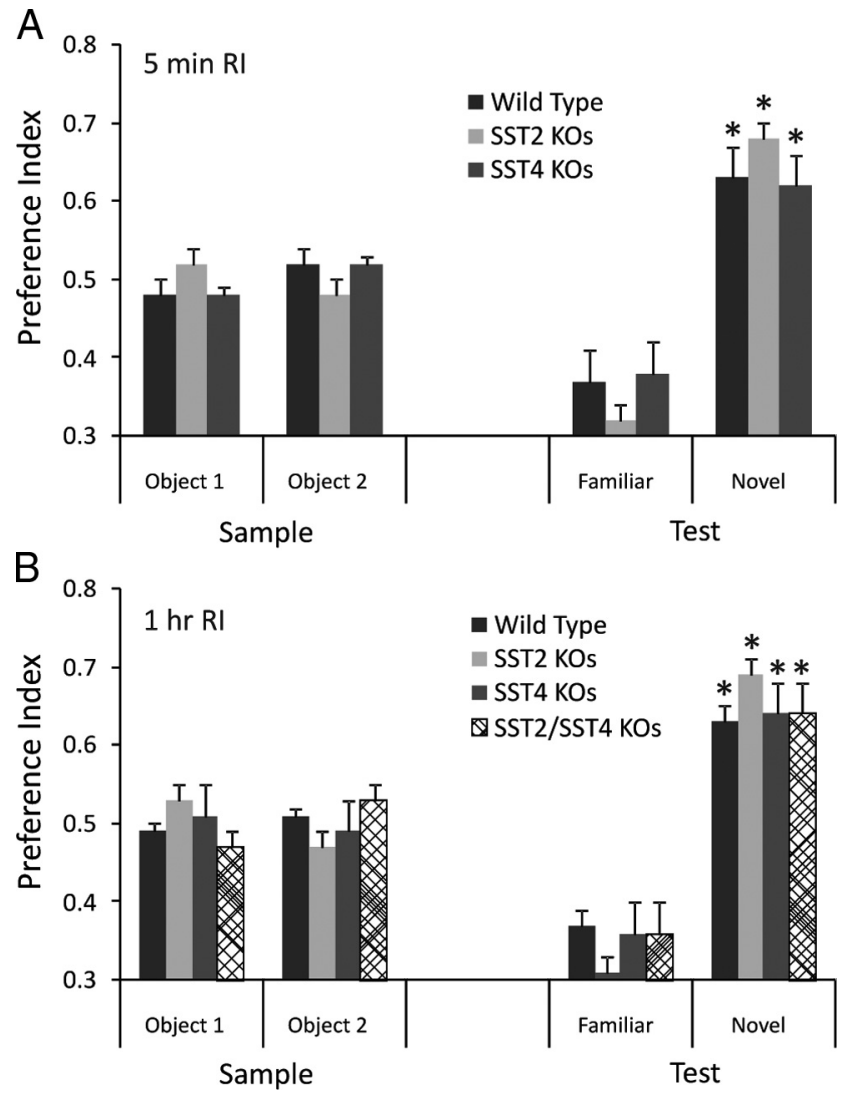

Figure 5. sst2, sst4, and sst2/sst4 double knock-outs show normal ORM. $\boldsymbol{A}$, When tested with a 5 min retention interval, $s s t 2$ and sst 4 knock-out mice are equal to wild-type mice in the ability to detect a novel object. $\boldsymbol{B}$, sst2, sst4, and sst2/sst4 knock-out mice show normal ability to discriminate a novel object after a $1 \mathrm{~h}$ retention interval. *Significant preference index (onesample $t$ test).

\section{Novel object recognition}

We tested wild-type, sst3 knock-out, and heterozygous $\left(s s t 3^{+/-}\right)$ mice for discrimination of object novelty after a single trial presentation. No significant differences among the different strains were observed in the total number of approaches to the two objects in the initial presentation phase $(p=0.645)$, showing that motivation to explore was not different between the strains. Wild-type mice showed a significant preference for the novel object at both $5 \mathrm{~min}(n=9)$ and $1 \mathrm{~h}(n=24)$ retention intervals (Fig. $3 A, B$ ). These results indicate that the wild-type mice recognized the familiar object to which they were previously exposed.

In contrast, the sst 3 knock-outs did not show any preference for the novel object with a $1 \mathrm{~h}$ retention interval $(n=20 ; p=0.5)$ (Fig. $3 B$ ). The preference index was significantly different between wild-type and sst 3 knock-out mice $(p=0.005)$. However, with a 5 min retention interval (Fig. $3 A$ ), sst3 knock-out mice demonstrated a significant preference for the novel object $(n=$ $12 ; p=0.01)$. There was no significant difference in preference index between sst 3 knock-outs and wild-type mice at the 5 min retention interval $(p=0.9)$. sst $3^{+/-}$mice showed a significant preference for the novel object with a $1 \mathrm{~h}$ retention interval $(n=$ $19 ; p=0.007)$. This was not significantly different from wild-type mice $(p=0.09)$.

To determine whether the deficit in sst 3 knock-outs observed with the $1 \mathrm{~h}$ delay could be alleviated by a more intensive training protocol, we tested the mice after three 5 min presentations with a $10 \mathrm{~min}$ intertrial interval (Fig. 4). Despite the more rigorous 

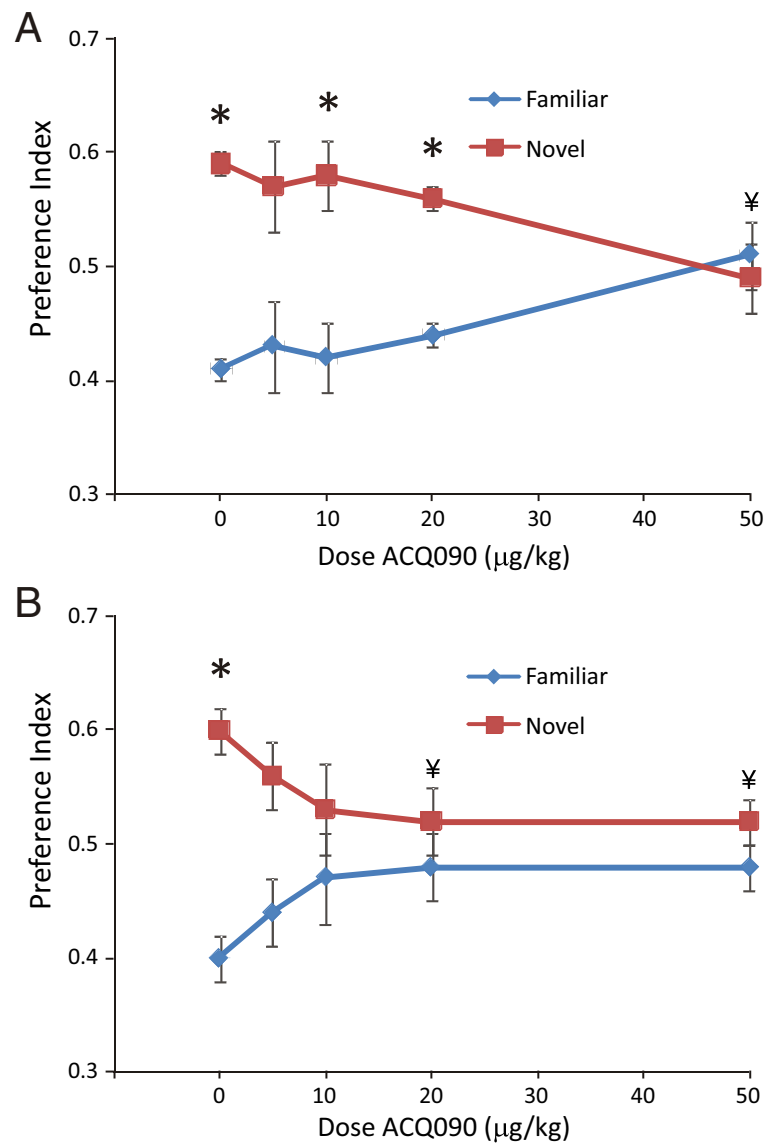

Figure 6. Injection of $\mathrm{SST}_{3}$ antagonist disrupts $\mathrm{ORM}$ after a $1 \mathrm{~h}$ retention interval in wild-type mice. $A, S_{S T}$ antagonist $\mathrm{ACQ090}$ injected intraperitoneally $30 \mathrm{~min}$ before sample phase blocks novel object discrimination at a dose of $50 \mu \mathrm{g} / \mathrm{kg} . \boldsymbol{B}$, Intraperitoneal injection of ACQ090 30 min before test phase blocks recall of object recognition memories at doses of 10,20 , and $50 \mu \mathrm{g} / \mathrm{kg}$. *Significant preference (one-sample $t$ test); ${ }^{*}$ significant difference from vehicle injections (unpaired $t$ test).

training, sst3 knock-outs still showed no preference for the novel object with a $1 \mathrm{~h}$ retention interval $(n=14 ; p=0.27)$, while wild-type mice demonstrated a significant preference $(n=13$; $p=0.001)$.

We also tested sst 2 and sst 4 knock-out mice for object memory. We previously showed that these two receptors exert a strong control over hippocampal excitability (Qiu et al., 2008). Neither sst2 nor sst 4 knock-outs showed deficits in ORM with a single presentation trial. The sst 2 knock-outs demonstrated significant preference for the novel object at both the $5 \mathrm{~min}$ (Fig. 5A) $(n=9$; $p=0.0001)$ and $1 \mathrm{~h}$ (Fig. $5 B)(n=11 ; p=0.005)$ retention intervals. Although sst 2 knock-outs showed a slightly stronger preference for the novel object at both retention intervals than the wild-type mice, they were not significantly different $(p=$ $0.1)$. sst 4 knock-outs also demonstrated significant preference for the novel object at both the $5 \mathrm{~min}(n=14 ; p=0.001)$ and the $1 \mathrm{~h}$ $(n=16 ; p=0.005)$ retention intervals, which were not different from wild-type mice ( $p=0.2$ for both retention intervals). We also tested sst2/sst 4 double knock-outs at the $1 \mathrm{~h}$ retention interval. These mice also demonstrated a significant preference for the novel object ( $n=8 ; p=0.009)$, which was not significantly different from wild-type mice (Fig. $5 B)(p=0.9)$.

To confirm a role for $\mathrm{SST}_{3}$ in ORM, we injected wild-type mice with the systemically active SST $_{3}$ antagonist ACQ090 (Bänziger et al., 2003) $30 \mathrm{~min}$ before initial presentation of objects. Using a $1 \mathrm{~h}$
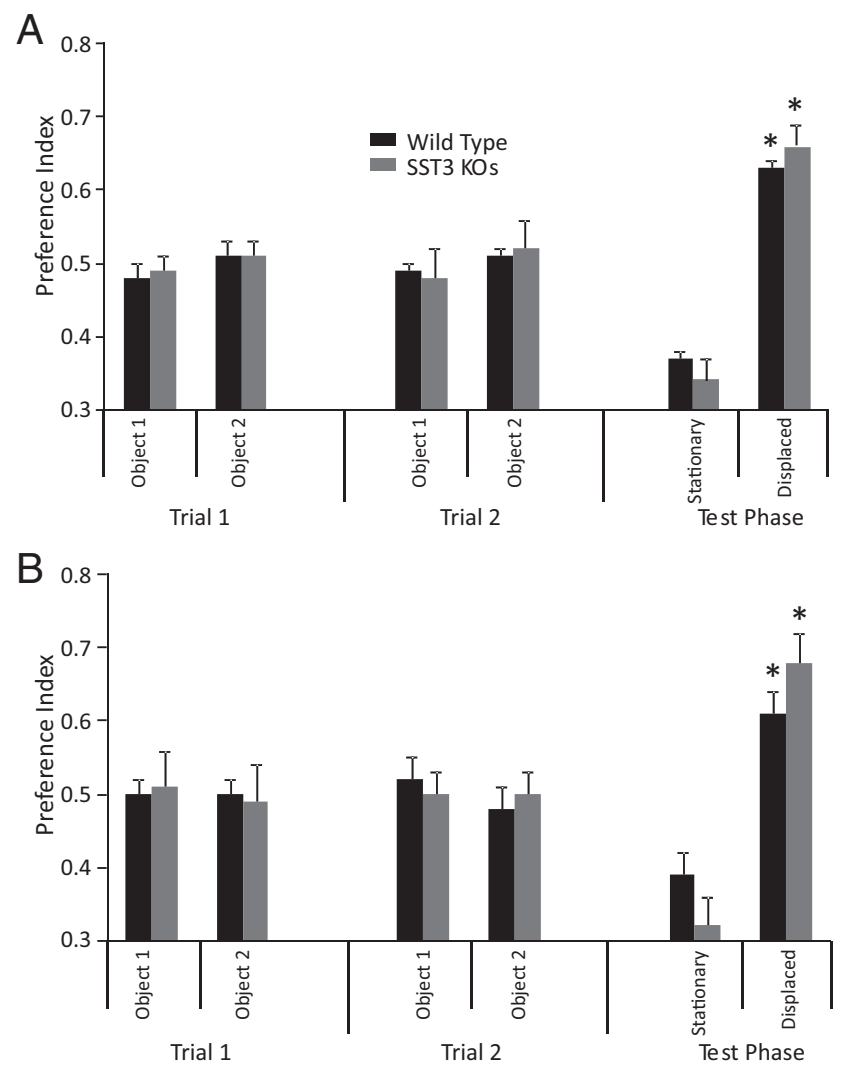

Figure 7. Memory for object location is normal in sst3 knock-out mice. When location of an object was moved from its position during training, sst3 knock-out mice showed equal preference for the displaced object as wild-type mice. $\boldsymbol{A}, 1 \mathrm{~h}$ retention interval. $\boldsymbol{B}, 2 \mathrm{~h}$ retention interval.

retention interval, we found that ACQ090 dose-dependently inhibited recognition of the familiar object (Fig. 6A). Mice injected with vehicle ( $0.1 \%$ DMSO in sterile saline; $n=13) 30$ min before the sample (acquisition) phase showed significant preference for the novel object $(p=0.009)$. However, mice injected with ACQ090 at $50 \mu \mathrm{g} / \mathrm{kg}(n=10)$ failed to demonstrate any preference for the novel object ( $p=0.3$ ). A significant drug effect was observed at this dose ( $p=0.02$ compared with vehicle). At lower doses $(5-20 \mu \mathrm{g} / \mathrm{kg})$, no drug effect was observed $(n=6-9)$. We then assessed the effect of the $\mathrm{SST}_{3}$ antagonist when injected after the sample phase, $30 \mathrm{~min}$ before the test phase, again using a $1 \mathrm{~h}$ retention interval (Fig. $6 \mathrm{~B}$ ). Performance of mice in discriminating between the novel and familiar object decreased with increasing doses of ACQ090 ( $n=6-14)$ (Fig. 6B). We observed a significant drug effect compared with vehicle $(n=10)$ at the 20 $\mu \mathrm{g} / \mathrm{kg}(n=6 ; p=0.045)$ and the $50 \mu \mathrm{g} / \mathrm{kg}$ dose $(n=7 ; p=0.02)$. Thus, $\mathrm{SST}_{3}$ blockade before both the sample phase and the test phase prevented recall of the familiar object; however, blockade before the test phase was sensitive to lower doses of ACQ090. With a 5 min retention interval, injection of ACQ090 $(20 \mu \mathrm{g} / \mathrm{kg})$ $30 \mathrm{~min}$ before the test phase did not disrupt ORM, as mice still showed significant preference for the novel object $(p=0.001$; $n=5)$.

\section{Object location memory}

We examined whether sst3 knock-out mice showed preference for an object that had been displaced from its previous location. This enables a more direct comparison of object and spatial memory relative to paradigms such as the Morris water maze, 
A

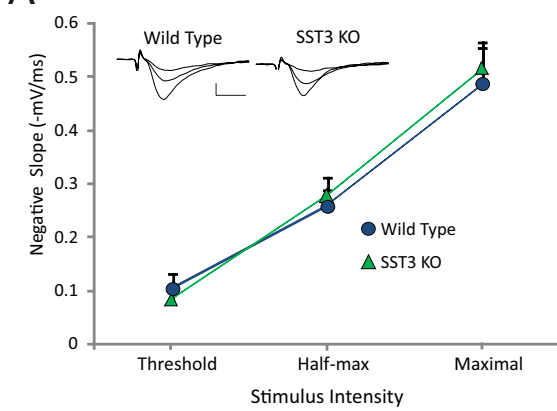

C

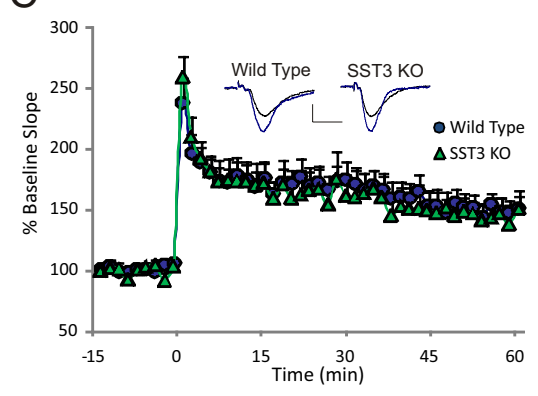

B

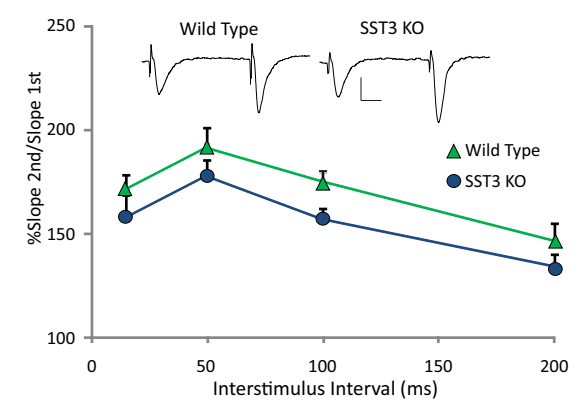

D

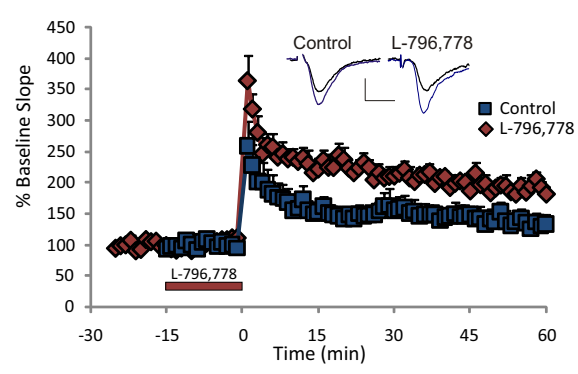

Figure 8. CA1 synaptic responses and electrically stimulated LTP in sst3 knock-out mice. $A, A$ plot of stimulus strength versus synaptic response shows basic excitatory neurotransmission in CA1 is normal in sst3 knock-outs. Representative voltage traces show response at three different stimulus intensities in wild-type and sst3 knock-out mice. $\boldsymbol{B}$, Paired-pulse facilitation at 15-200 ms interstimulus intervals is normal in sst3 knock-out mice. Representative voltage traces at 50 ms interstimulus intervals in wild-type and sst3 knock-out mice. C, CA1 LTP generated by stimulation of the Schaeffer collaterals with two HFTs is normal in sst3 knock-outs. D, Application of SST 3 agonist L-796,778 (1 $\mu \mathrm{M})$ increases LTP induced by two HFTs in wild-type mice. Red bar shows time of application (0-16 min). Insets show representative fEPSPs for each condition: black traces are baseline, blue traces are 60 min following the trains. In this and subsequent figures, stimulus artifacts are digitally truncated. Calibration: $0.5 \mathrm{mV}, 10 \mathrm{~ms}$.

which requires different sensory and motor functions and is more stressful (Dere et al., 2007). With a two-trial training strategy, sst3 knock-out mice showed equal preference for the displaced object as wild-type mice, with both a $1 \mathrm{~h}$ retention interval (Fig. 7A) (wild-type, $n=26$; sst3 knock-outs, $n=21$ ) and a $2 \mathrm{~h}$ retention interval (Fig. $7 B)(n=8$ for both wild-type and $s s t 3$ knock-outs). Thus, at retention intervals where clear deficits in ORM are apparent sst 3 knock-out mice show no deficit in memory of object location.

\section{Long-term potentiation in CA1 hippocampus}

To determine whether deficits in object memory were correlated with deficits in synaptic transmission or plasticity, we assessed synaptic responses in CA1 of hippocampus. Normal glutamatergic synaptic transmission generated by a single stimulus to the Schaffer collaterals was similar in wild-type mice $(n=7)$ and sst 3 knock-out mice $(n=6)$ (Fig. $8 A$ ). Paired-pulse facilitation evoked at intervals from 15 to 200 ms was not significantly different in sst3 knock-out mice compared with wild-type mice $(p=0.5)$ (Fig. $8 B$ ). When LTP was evoked by application of two HFTs to the Schaffer collaterals, LTP in sst3 knock-outs was not different from wild-type mice (Fig. $8 C)(p=0.8)$. However, superfusion of the $\mathrm{SST}_{3}$ agonist L-796,778 $(1 \mu \mathrm{M} ; n=5)$ significantly increased LTP in wild-type mice (Fig. 8D) $(p=0.04)$.

Regulation of cAMP pathways is a critical component of signaling in many distinct types of cilia, both primary (Masyuk et al., 2006; Smith et al., 2006; Takeuchi and Kurahashi, 2008) and motile (Banizs et al., 2005; Schmid et al., 2007). To determine whether dysregulation of cAMP-mediated synaptic plasticity was present in sst3 knock-out mice, we evoked CA1 LTP with forsko- lin, a direct activator of AC. Forskolin in the presence of IBMX and bicuculline produces robust and long-lasting synaptic potentiation in hippocampal slices from wild-type mice $(n=16)$ (Fig. $9 A)$. However, in sst3 knock-outs forskolin potentiated the synaptic response acutely, but after the drugs were washed off the degree of potentiation was greatly reduced compared with wild-type mice. After $1 \mathrm{~h}$ of forskolin washout, in sst3 knock-outs the fEPSP slope was significantly less than in wild-type mice, $135 \pm 7.2 \%$ of baseline $(n=13)$, compared with $205 \pm 8.1 \%$ in wild-type mice $(p=0.03)$. To validate that this was a direct effect of sst 3 deletion, we assessed the effect of the $\mathrm{SST}_{3}$ antagonist on forskolin-induced LTP. ACQ090 did not affect baseline synaptic transmission. In the presence of $0.5 \mu \mathrm{M}$ ACQ090, forskolin produces a small transient potentiation of fEPSPs that returns to $122 \pm$ $12 \%$ of baseline $60 \mathrm{~min}$ following washout $(n=9)$ (Fig. 9B). In nontreated control slices, fEPSP slopes remained at $180 \pm$ $15 \%$ above baseline levels $60 \mathrm{~min}$ following drug wash $(n=10)$. Thus, activation of $\mathrm{SST}_{3}$ appears to be important for induction of cAMP-evoked synaptic potentiation. We also tested whether $\mathrm{SST}_{3}$ blockade affected forskolin-stimulated LTP when applied after induction. In these experiments, $0.5 \mu \mathrm{M}$ ACQ090 was applied immediately following the forskolin mixture and throughout the following $60 \mathrm{~min}$ (Fig. 9B). With this application paradigm, we observed no difference in the degree of potentiation $1 \mathrm{~h}$ following forskolin application $(n=6)$ compared with control $(p=0.6)$. To verify specificity of ACQ090, we assessed its ability to modulate forskolin LTP in sst3 knock-out mice. ACQ090 did not cause further reduction of forskolin LTP in sst3 knock-outs (132 $\pm 16 \%$ of baseline 60 min following washout of forskolin; $n=8)$.

\section{Measurement of cAMP levels in hippocampus from wild-type and sst 3 knock-out mice}

Since $\mathrm{SST}_{3}$ activation is critical for induction of forskolin-evoked LTP, we examined hippocampal cAMP levels in sst 3 knock-out mice. We found that cAMP levels in sst 3 knock-out mice were $41.5 \pm 13 \%$ of wild-type mice when extracted directly from hippocampus ( $n=6$ each; $p<0.05$ ). We also examined forskolininduced increases in cAMP in hippocampal lysate from wild-type and sst3 knock-out mice. Unstimulated cAMP levels in lysates were also significantly lower in sst3 knock-out mice ( $820 \pm 312$ $\mathrm{pmol} / \mathrm{mg}$ protein) compared with wild-type mice $(1299 \pm 144$ $\mathrm{pmol} / \mathrm{mg}$ protein). However, forskolin induced a similar relative increase in cAMP in hippocampal lysates from wild-type mice $(5.1 \pm 1.7$-fold increase; $n=5)$ and sst 3 knock-out mice (4.8 \pm 0.4 -fold increase; $n=5$ ). We also examined the effect of the $\mathrm{SST}_{3}$ agonist and antagonist in hippocampal lysate $(n=5)$ and in hippocampal slices $(n=5)$ (Fig. 10). In hippocampal lysate, blockade of $\mathrm{SST}_{3}$ with ACQ090 $(1 \mu \mathrm{M})$ did not significantly affect forskolin-stimulated cAMP levels ( $91 \pm 15 \%$ of control; $p=0.6$ ). However, in hippocampal slices, ACQ090 reduced forskolin- 

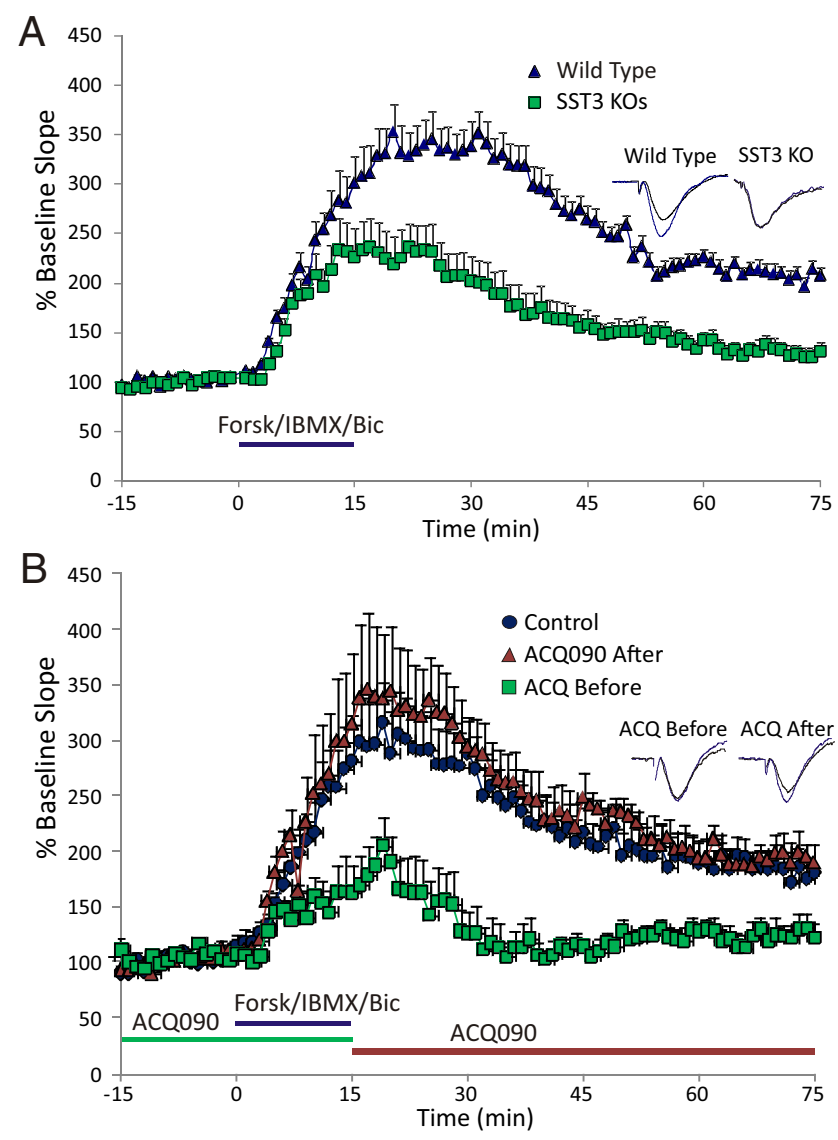

Figure 9. $\mathrm{SST}_{3}$ is critical for mediation of LTP induced by activation of AC. A, Forskolinstimulated LTP is impaired in sst3 knock-out mice. Forskolin/IBMX stimulates some acute synaptic potentiation in sst3 knock-outs, but little sustained potentiation is maintained after washout. Blue bar indicates time of forskolin/IBMX application. B, Superfusion of $\mathrm{SST}_{3}$ antagonist ACQ090 (0.5 $\mu \mathrm{m}$; green bar) before and during forskolin application (blue bar) limits generation of LTP. When ACQ090 is applied following the forskolin application (orange bar), no LTP deficit is observed. Insets show representative fEPSPs for each condition, black traces are baseline, gray traces are $60 \mathrm{~min}$ following the washout of the forskolin mixture. Calibration: $0.5 \mathrm{mV}$, $10 \mathrm{~ms}$.

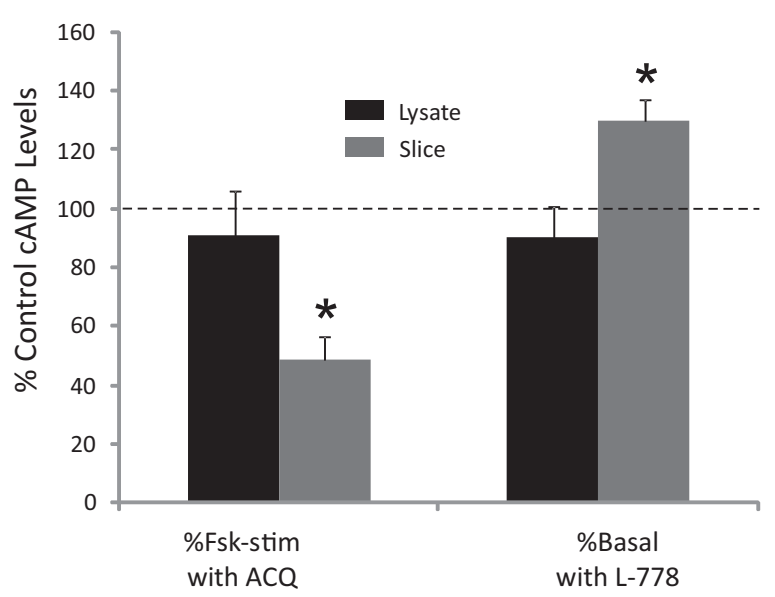

Figure 10. Effects of $\mathrm{SST}_{3}$ agonist and antagonist in hippocampal lysate and slices. Forskolin (Fsk) stimulation of CAMP is inhibited by $1 \mu \mathrm{M} \mathrm{ACQ090} \mathrm{in} \mathrm{hippocampal} \mathrm{slices} \mathrm{but}$ not hippocampal lysate. The SST agonist L-796,778 (L-778) increases basal cAMP levels in hippocampal slices but not hippocampal lysate. ${ }^{*}$ Significant difference from control cAMP levels (basal or forskolin-stimulated in the absence of $\mathrm{SST}_{3}$ ligand; dashed line). stimulated cAMP levels to $48.6 \pm 8 \%$ of control levels ( $p=0.03$ ). Similarly, SST3 activation with L-796,779 (1 $\mu \mathrm{M})$ did not affect basal cAMP levels in hippocampal lysate $(90 \pm 11 \%$; $n=0.4)$, but in hippocampal slices increased basal cAMP levels to $130 \pm 7 \%$ of control levels $(p=0.03)$. These results suggest that intact cilia and/or neuronal structure may be required for $\mathrm{SST}_{3}$ signaling.

\section{Discussion}

As confirmed in this study, the $\mathrm{SST}_{3}$ receptor is expressed exclusively on primary neuronal cilia in brain (Händel et al., 1999). Primary cilia are nonmotile microtubule-based structures found on many cells in the body and brain (Fuchs and Schwark, 2004). The cilia membrane is continuous with the plasma membrane but has a distinct set of membrane proteins. The function of primary cilia outside of sensory cells has been until recently obscure, and there was some consideration that they were vestigial (Pazour and Witman, 2003). Recent links to mutations in ciliaspecific genes and human diseases, however, have generated a surge of interest in these structures (Eley et al., 2005).

In this study, we take advantage of the specific ciliary location of $\mathrm{SST}_{3}$ to examine the function of neuronal cilia using sst3 knock-out mice. That no major changes in cilia structure or number occur in sst3 knock-out mice provides an additional advantage, since many previous studies on cilia function have relied on mouse models with obvious disruption of the cilia itself (Breunig et al., 2008; Spassky et al., 2008). Further, SST $_{3}$ expression in rodents appears postnatally, peaking in young adults (Stanić et al., 2009); thus, sst3 knock-out mice do not have the major disruptions in brain development that occur with knock out of many cilia-specific genes (Banizs et al., 2005; Town et al., 2008). Examining the function of this constituent receptor provides a window to understanding cilia signaling in mature neurons.

The role of cilia signaling in learning and memory has not been investigated, although ciliary defects that underlie BBS and Joubert syndrome are associated with mental retardation (Adams et al., 2007). However, since many developmental brain abnormalities are also apparent (Pan et al., 2005), a definitive link between cilia dysfunction and cognitive defects has not been established. We tested sst 3 knock-out mice in spontaneous exploration tasks to test both spatial memory and object recognition memory. Object displacement studies can be done side by side with object recognition studies, allowing comparison of spatial and recognition memory using similar tasks conducted in the same environment and that recruit the same sensory modalities and motor function (Dere et al., 2007). Our results using these paradigms show that $\mathrm{SST}_{3}$ is critical for ORM but not spatial memory. That ORM is intact in sst3 knock-outs with a 5 min retention interval suggests that these mice are able to acquire object information but not maintain the representation over longer retention intervals. Overtraining, in which we used a three-trial presentation strategy, did not rescue the object memory impairment in sst 3 knock-out mice.

Injection of the $\mathrm{SST}_{3}$ antagonist after the acquisition phase produced a deficit in recall of familiar objects. Although blockade of $\mathrm{SST}_{3}$ receptors before the sample phase could also impair object recognition, this may be due to residual antagonist remaining during the test phase at highest doses. However, further studies are required to more specifically characterize how $\mathrm{SST}_{3}$ activation contributes to recognition memory.

Knock out of $\mathrm{SST}_{3}$ did not impair memory for object location. Dissociation between spatial memory and ORM has been previously reported. Of particular note, some disruptions of cAMP signaling pathways impact ORM but not spatial memory. Knock 
out of ACVIII inhibits (Zhang et al., 2008) while overexpression of ACI enhances ORM in mice (Garelick et al., 2009), although neither manipulation impacts spatial memory. Broadly increasing AC activity by knocking out the inhibitory G-protein $G_{i \alpha 1}$ disrupts ORM without affecting spatial memory (Pineda et al., 2004). These studies suggest that tight regulation of the cAMP signaling system is critical for ORM, while spatial memory appears to be less sensitive to such manipulations.

Regulation of cAMP pathways is a common motif in ciliary signaling. The restricted spatial structure of the cilia allows for rapid diffusion of small molecules. Typically, cilia that respond to light or chemicals (i.e., odorants) rely on cyclic nucleotides (cAMP or cGMP) to mediate signaling. In kidney cilia, $\mathrm{Ca}^{2+}$ mediated changes in cAMP levels are critical to detection of fluid flow and to the pathogenesis of polycystic kidney disease (Smith et al., 2006). Additionally, olfactory transduction involves increasing cAMP through activation of ACIII, which is localized in cilia of olfactory epithelial cells (Restrepo et al., 1996) and is also expressed in cilia of central neurons, including hippocampus (Bishop et al., 2007).

Although we found normal electrically evoked CA1 LTP in sst3 knock-outs, forskolin-stimulated LTP, where AC is directly stimulated, is disrupted in both sst 3 knock-out mice and with acute $\mathrm{SST}_{3}$ blockade. Although $\mathrm{SST}_{3}$ activation is not required for electrically stimulated LTP, it can enhance this form of LTP, similar to other drugs that increase intracellular cAMP (Gelinas and Nguyen, 2005). The mechanisms through which direct stimulation of AC leads to LTP are unclear, although the activation gene transcription appears critical (Nguyen and Woo, 2003). That activation of $\mathrm{SST}_{3}$ is critical for inducing forskolin LTP suggests signaling in cilia, possibly through stimulation of ACIII, may be an important underlying mechanism.

The dramatic reduction of basal cAMP levels in hippocampus of sst 3 knock-outs indicates that SST signaling in cilia is necessary for cell-wide maintenance of cAMP levels in neurons. Interestingly, a recent study showed a reduction in forskolin-stimulated AC activity in hypothalamus of ACIII knock-out mice, although basal AC activity was only modestly reduced (Wang et al., 2009). On the other hand, in $\mathrm{SST}_{3}$ knock-out mice, when normalized to the different basal levels, forskolin stimulation of cAMP levels in hippocampal lysate is not impaired. Likewise, the $\mathrm{SST}_{3}$ agonist and antagonist do not regulate cAMP levels in hippocampal lysate. However, in hippocampal slices, where cilia and neuronal structure are largely intact, blockade of $\mathrm{SST}_{3}$ reduces forskolin stimulation of cAMP, and activation of $\mathrm{SST}_{3}$ increases basal cAMP levels. These studies suggest that $\mathrm{SST}_{3}$-dependent signaling depends on the integrity of the cilium for amplification to the neuronal soma.

The cilium may act as a coincidence detector. Stimulation of ACIII in the absence of SST would not lead to activation of downstream signaling events. The endogenous activator of ACIII in hippocampus is not known; in olfactory cilia, ACIII is stimulated by $G_{s}$-like $G$-proteins $\left(G_{\text {olf }}\right)$ that couple to odorant receptors (Wang and Storm, 2003). In addition to $\mathrm{SST}_{3}$, the only $\mathrm{G}$ proteincoupled receptor that has been positively identified on neuronal cilia in hippocampus is another peptide receptor, MCHR1, that typically inhibits forskolin-evoked cAMP levels in expression systems (Pissios et al., 2003). However, activation of the endogenous receptor can increase cAMP levels (Verlaet et al., 2002), suggesting $\mathrm{G}_{\mathrm{s}}$ coupling may occur in vivo. Interestingly, melanin concentrating hormone $(\mathrm{MCH})$, the endogenous ligand for MCHR1, has procognitive effects in hippocampus (Monzon et al., 1999), and, as in $\mathrm{SST}_{3}$ knock-outs, no spatial learning deficits are appar- ent in MCHR1 knock-out mice (Lalonde and Qian, 2007). In hippocampus, $\mathrm{MCH}$ is expressed largely in pyramidal neurons of CA1 and CA3 (Saito et al., 2001). Thus, coordinate highfrequency firing of pyramidal neurons and SST-containing interneurons, such as occurs during exploration (Nitz and McNaughton, 2004), could cause corelease of both peptides, activating signaling pathways involved in ORM.

A question not addressed in our study is the specific mechanism through which $\mathrm{SST}_{3}$ modulates cAMP signaling. Since in vitro studies suggest $\mathrm{SST}_{3}$ is linked to $\mathrm{G}_{\mathrm{i}} / \mathrm{G}_{\mathrm{o}} \mathrm{G}$-proteins, which inhibit AC (Yasuda et al., 1992), it seems paradoxical that $\mathrm{SST}_{3}$ activation increases cAMP levels and its antagonism robustly inhibits forskolin-evoked increases in cAMP. That $\mathrm{SST}_{3}$ activation is required for full stimulation of $\mathrm{AC}$ by forskolin, a direct activator of AC, suggests the receptor may be acting upstream of ACIII, perhaps blocking an inhibitory constraint such as CaM kinase II, a well established inhibitor of ACIII (Wei et al., 1996). Alternatively, activation of ACIII could generate $\mathrm{a} \mathrm{Ca}^{2+}$ transient that is transmitted to and amplified in the neuronal soma, as in olfactory cilia (Zufall et al., 2000). This could activate $\mathrm{Ca}^{2+}$. dependent ACs such as ACI and ACVIII, leading to a secondary wave of cAMP. Indeed, it is unlikely that the robust inhibition of forskolin-stimulated cAMP levels by $\mathrm{SST}_{3}$ antagonism, or the large decreases in cAMP levels in $\mathrm{SST}_{3}$ knock-out mice, can be fully accounted for by cAMP signaling within the cilia, which comprise a miniscule portion of neuronal volume. Likewise, the robust deficit in forskolin activation of AC activity in ACIII knock-out mice would also likely involve activation of other AC isoforms in the cell soma through amplification into the soma of cilia-based signaling events (Wang et al., 2009). Activation of $\mathrm{SST}_{3}$ could be essential to signaling between the initial ACIII activation and the downstream activation of $\mathrm{Ca}^{2+}$-dependent ACs.

Our results demonstrate that SST signaling in neuronal cilia is critical for novelty detection. Cilia extruding into the extracellular space are coated with $\mathrm{SST}_{3}$, suggesting they are sensitive detectors of increases in SST levels such as would occur during high-frequency neuronal firing (Fanselow et al., 2008). Decreased SST levels found in hippocampus and cortex in Alzheimer's disease (Burgos-Ramos et al., 2008) could contribute to deficits in recognition memory in these patients. Thus, $\mathrm{SST}_{3}$ could be a novel target in treatment of dementia and other types of cognitive impairment.

\section{References}

Adams NA, Awadein A, Toma HS (2007) The retinal ciliopathies. Ophthalmic Genet 28:113-125.

Banizs B, Pike MM, Millican CL, Ferguson WB, Komlosi P, Sheetz J, Bell PD, Schwiebert EM, Yoder BK (2005) Dysfunctional cilia lead to altered ependyma and choroid plexus function, and result in the formation of hydrocephalus. Development 132:5329-5339.

Bänziger M, Cercus J, Hirt H, Laumen K, Malan C, Spindler F, Struber F, Troxler T (2003) The development of a practical synthesis of the potent and selective somatostatin sst3 receptor antagonist [4-(3,4-difluorophenyl)-piperazine-1-yl]-\{(4S,4aS,8aR)-2[(S)-3-(6-methoxy-pyridin-3-yl)2-methyl-propyl]-decahydroisoquinoline-4-yl\}-methanone (NVP-ACQ090). Tetrahedron Asymmetry 14:3469-3477.

Baraban SC, Tallent MK (2004) Interneuron diversity series: interneuronal neuropeptides - endogenous regulators of neuronal excitability. Trends Neurosci 27:135-142.

Baratta MV, Lamp T, Tallent MK (2002) Somatostatin depresses long-term potentiation and $\mathrm{Ca} 2+$ signaling in mouse dentate gyrus. J Neurophysiol 88:3078-3086.

Berbari NF, Lewis JS, Bishop GA, Askwith CC, Mykytyn K (2008a) BardetBiedl syndrome proteins are required for the localization of $G$ proteincoupled receptors to primary cilia. Proc Natl Acad Sci U S A 105:4242-4246. Berbari NF, Johnson AD, Lewis JS, Askwith CC, Mykytyn K (2008b) Iden- 
tification of ciliary localization sequences within the third intracellular loop of G protein-coupled receptors. Mol Biol Cell 19:1540-1547.

Bishop GA, Berbari NF, Lewis J, Mykytyn K (2007) Type III adenylyl cyclase localizes to primary cilia throughout the adult mouse brain. J Comp Neurol 505:562-571.

Breunig JJ, Sarkisian MR, Arellano JI, Morozov YM, Ayoub AE, Sojitra S, Wang B, Flavell RA, Rakic P, Town T (2008) Primary cilia regulate hippocampal neurogenesis by mediating sonic hedgehog signaling. Proc Natl Acad Sci U S A 105:13127-13132.

Burgos-Ramos E, Hervás-Aguilar A, Aguado-Llera D, Puebla-Jiménez L, Hernández-Pinto AM, Barrios V, Arilla-Ferreiro E (2008) Somatostatin and Alzheimer's disease. Mol Cell Endocrinol 286:104-111.

Davenport JR, Watts AJ, Roper VC, Croyle MJ, van Groen T, Wyss JM, Nagy TR, Kesterson RA, Yoder BK (2007) Disruption of intraflagellar transport in adult mice leads to obesity and slow-onset cystic kidney disease. Curr Biol 17:1586-1594.

Dere E, Huston JP, De Souza Silva MA (2007) The pharmacology, neuroanatomy and neurogenetics of one-trial object recognition in rodents. Neurosci Biobehav Rev 31:673-704.

Eley L, Yates LM, Goodship JA (2005) Cilia and disease. Curr Opin Genet Dev 15:308-314.

Fanselow EE, Richardson KA, Connors BW (2008) Selective, statedependent activation of somatostatin-expressing inhibitory interneurons in mouse neocortex. J Neurophysiol 100:2640-2652.

Fuchs JL, Schwark HD (2004) Neuronal primary cilia: a review. Cell Biol Int 28:111-118.

Garelick MG, Chan GC, DiRocco DP, Storm DR (2009) Overexpression of type I adenylyl cyclase in the forebrain impairs spatial memory in aged but not young mice. J Neurosci 29:10835-10842.

Gelinas JN, Nguyen PV (2005) Beta-adrenergic receptor activation facilitates induction of a protein synthesis-dependent late phase of long-term potentiation. J Neurosci 25:3294-3303.

Han YG, Spassky N, Romaguera-Ros M, Garcia-Verdugo JM, Aguilar A, Schneider-Maunoury S, Alvarez-Buylla A (2008) Hedgehog signaling and primary cilia are required for the formation of adult neural stem cells. Nat Neurosci 11:277-284.

Händel M, Schulz S, Stanarius A, Schreff M, Erdtmann-Vourliotis M, Schmidt H, Wolf G, Höllt V (1999) Selective targeting of somatostatin receptor 3 to neuronal cilia. Neuroscience 89:909-926.

Hervieu G, Emson PC (1998) Visualisation of non-glycosylated somatostatin receptor two (ngsst2) immunoreactivity in the rat central nervous system. Brain Res Mol Brain Res 58:138-155.

Ibañez-Tallon I, Pagenstecher A, Fliegauf M, Olbrich H, Kispert A, Ketelsen UP, North A, Heintz N, Omran H (2004) Dysfunction of axonemal dynein heavy chain Mdnah5 inhibits ependymal flow and reveals a novel mechanism for hydrocephalus formation. Hum Mol Genet 13:21332141.

Lalonde R, Qian S (2007) Exploratory activity, motor coordination, and spatial learning in Mchrl knockout mice. Behav Brain Res 178:293-304.

Masyuk AI, Masyuk TV, Splinter PL, Huang BQ, Stroope AJ, LaRusso NF (2006) Cholangiocyte cilia detect changes in luminal fluid flow and transmit them into intracellular Ca2 + and cAMP signaling. Gastroenterology 131:911-920.

Monzon ME, de Souza MM, Izquierdo LA, Izquierdo I, Barros DM, de Barioglio SR (1999) Melanin-concentrating hormone (MCH) modifies memory retention in rats. Peptides 20:1517-1519.

Nguyen PV, Woo NH (2003) Regulation of hippocampal synaptic plasticity by cyclic AMP-dependent protein kinases. Prog Neurobiol 71:401-437.

Nitz D, McNaughton B (2004) Differential modulation of CA1 and dentate gyrus interneurons during exploration of novel environments. J Neurophysiol 91:863-872.

Pan J, Wang Q, Snell WJ (2005) Cilium-generated signaling and ciliarelated disorders. Lab Invest 85:452-463.

Pazour GJ, Witman GB (2003) The vertebrate primary cilium is a sensory organelle. Curr Opin Cell Biol 15:105-110.

Pineda VV, Athos JI, Wang H, Celver J, Ippolito D, Boulay G, Birnbaumer L,
Storm DR (2004) Removal of G(ialpha1) constraints on adenylyl cyclase in the hippocampus enhances LTP and impairs memory formation. Neuron 41:153-163.

Pissios P, Trombly DJ, Tzameli I, Maratos-Flier E (2003) Melaninconcentrating hormone receptor 1 activates extracellular signal-regulated kinase and synergizes with $\mathrm{G}(\mathrm{s})$-coupled pathways. Endocrinology 144:3514-3523.

Qiu C, Zeyda T, Johnson B, Hochgeschwender U, de Lecea L, Tallent MK (2008) Somatostatin receptor subtype 4 couples to the M-current to regulate seizures. J Neurosci 28:3567-3576.

Ramírez JL, Mouchantaf R, Kumar U, Otero Corchon V, Rubinstein M, Low MJ, Patel YC (2002) Brain somatostatin receptors are up-regulated in somatostatin-deficient mice. Mol Endocrinol 16:1951-1963.

Restrepo D, Teeter JH, Schild D (1996) Second messenger signaling in olfactory transduction. J Neurobiol 30:37-48.

Saito Y, Cheng M, Leslie FM, Civelli O (2001) Expression of the melaninconcentrating hormone $(\mathrm{MCH})$ receptor mRNA in the rat brain. J Comp Neurol 435:26-40.

Schmid A, Sutto Z, Nlend MC, Horvath G, Schmid N, Buck J, Levin LR, Conner GE, Fregien N, Salathe M (2007) Soluble adenylyl cyclase is localized to cilia and contributes to ciliary beat frequency regulation via production of cAMP. J Gen Physiol 130:99-109.

Smith LA, Bukanov NO, Husson H, Russo RJ, Barry TC, Taylor AL, Beier DR, Ibraghimov-Beskrovnaya O (2006) Development of polycystic kidney disease in juvenile cystic kidney mice: insights into pathogenesis, ciliary abnormalities, and common features with human disease. J Am Soc Nephrol 17:2821-2831.

Spassky N, Han YG, Aguilar A, Strehl L, Besse L, Laclef C, Ros MR, GarciaVerdugo JM, Alvarez-Buylla A (2008) Primary cilia are required for cerebellar development and Shh-dependent expansion of progenitor pool. Dev Biol 317:246-259.

Stanić D, Malmgren H, He H, Scott L, Aperia A, Hökfelt T (2009) Developmental changes in frequency of the ciliary somatostatin receptor 3 protein. Brain Res 1249:101-112.

Takeuchi H, Kurahashi T (2008) Distribution, amplification, and summation of cyclic nucleotide sensitivities within single olfactory sensory cilia. J Neurosci 28:766-775.

Town T, Breunig JJ, Sarkisian MR, Spilianakis C, Ayoub AE, Liu X, Ferrandino AF, Gallagher AR, Li MO, Rakic P, Flavell RA (2008) The stumpy gene is required for mammalian ciliogenesis. Proc Natl Acad Sci U S A 105:2853-2858.

Verlaet M, Adamantidis A, Coumans B, Chanas G, Zorzi W, Heinen E, Grisar T, Lakaye B (2002) Human immune cells express ppMCH mRNA and functional MCHR1 receptor. FEBS Lett 527:205-210.

Wang H, Storm DR (2003) Calmodulin-regulated adenylyl cyclases: crosstalk and plasticity in the central nervous system. Mol Pharmacol 63:463-468.

Wang Z, Li V, Chan GC, Phan T, Nudelman AS, Xia Z, Storm DR (2009) Adult type 3 adenylyl cyclase-deficient mice are obese. PLoS One 4:e6979.

Wei J, Wayman G, Storm DR (1996) Phosphorylation and inhibition of type III adenylyl cyclase by calmodulin-dependent protein kinase II in vivo. J Biol Chem 271:24231-24235.

Yasuda K, Rens-Domiano S, Breder CD, Law SF, Saper CB, Reisine T, Bell GI (1992) Cloning of a novel somatostatin receptor, SSTR3, coupled to adenylycyclase. J Biol Chem 267:20422-20428.

Zhang M, Moon C, Chan GC, Yang L, Zheng F, Conti AC, Muglia L, Muglia LJ, Storm DR, Wang H (2008) Ca-stimulated type 8 adenylyl cyclase is required for rapid acquisition of novel spatial information and for working/episodic-like memory. J Neurosci 28:4736-4744.

Zheng H, Bailey A, Jiang MH, Honda K, Chen HY, Trumbauer ME, Van der Ploeg LH, Schaeffer JM, Leng G, Smith RG (1997) Somatostatin receptor subtype 2 knockout mice are refractory to growth hormone-negative feedback on arcuate neurons x. Mol Endocrinol 11:1709-1717.

Zufall F, Leinders-Zufall T, Greer CA (2000) Amplification of odor-induced $\mathrm{Ca}(2+)$ transients by store-operated $\mathrm{Ca}(2+)$ release and its role in olfactory signal transduction. J Neurophysiol 83:501-512. 